\title{
Analysis on rock fracture signals and exploration of infrared advance prediction under true triaxial loading
}

\author{
jiawang hao ${ }^{1}$, lan qiao ${ }^{1}$, zhanjin $\mathrm{li}^{2}$, and Qingwen $\mathrm{Li}^{1}$ \\ ${ }^{1}$ University of Science and Technology Beijing \\ ${ }^{2}$ North China University of Science and Technology
}

March 12, 2021

\begin{abstract}
To predict the fractured rock failure under deep triaxial stress in advance, the true triaxial tests were carried out using thermal infrared monitoring and acoustic emission (AE). This paper proposes "infrared temperature jumping rate (ITJR)" to reflect the "jumpiness" of the temperature field matrix, and establishes an infrared advance prediction method. The results show that the high temperature area will converge and expand gradually, and cracks propagate along a certain direction. In the sudden temperature reduction area, the rock stripping is easy to occur. At the boundary between high-low temperature areas, it is easy to produce breakage cracks and form rock spalling. In the short quiet period, the rock gradually gathers strain energy, which will be released in the fracture period. By comparing the time of AE sudden increase with the time of ITJR mutation, it shows that the method has a good advance prediction effect for rock fracture.
\end{abstract}

\section{Hosted file}

Manuscript.pdf available at https://authorea.com/users/401141/articles/513337-analysison-rock-fracture-signals-and-exploration-of-infrared-advance-prediction-under-truetriaxial-loading

\section{Hosted file}

Figures.docx available at https://authorea.com/users/401141/articles/513337-analysison-rock-fracture-signals-and-exploration-of-infrared-advance-prediction-under-truetriaxial-loading 